\title{
Evaluation of Taenia solium and Taenia crassiceps cysticercal antigens for immunodiagnosis of neurocysticercosis using ELISA on cerebrospinal fluid samples
}

\author{
Avaliação de antígenos de cisticercos de Taenia solium e Taenia crassiceps \\ para o imunodiagnóstico da neurocisticercose por ELISA \\ em amostras de líquido cefalorraquidiano
}

Lisandra Akemi Suzuki ${ }^{1}$, Gisele Cristina Arruda ${ }^{1}$, Elizabeth Maria Aparecida Barasnevicius Quagliato² and Cláudio Lúcio Rossi ${ }^{1}$

\begin{abstract}
The efficacy of whole parasite and vesicular fluid antigen extracts from Taenia solium and Taenia crassiceps cysticerci for immunodiagnosis of neurocysticercosis was evaluated using ELISA on cerebrospinal fluid samples. Anticysticercal IgG antibodies were assayed in cerebrospinal fluid samples from 23 patients with neurocysticercosis and 35 patients with other neurological disorders. The ELISA reaction for the whole Taenia solium cysticercal extract showed $91.3 \%$ sensitivity and 94.3\% specificity, whereas the sensitivity and specificity of the ELISA for the whole Taenia crassiceps cysticercal extract were $87 \%$ and $94.3 \%$, respectively. The ELISA reactions for vesicular fluid from Taenia solium or Taenia crassiceps showed $91.3 \%$ sensitivity and $97.1 \%$ specificity. Considering the results obtained from the four antigen preparations, vesicular fluid from Taenia solium and Taenia crassiceps cysticerci may be useful as a source of antigens for immunological reactions that are used for detecting specific antibodies in cerebrospinal fluid samples from patients with neurocysticercosis.
\end{abstract}

Key-words: Neurocysticercosis. Cysticercal antigens. ELISA.

\section{RESUMO}

A eficácia de extratos antigênicos de parasitas totais e líquido vesicular de cisticercos de Taenia solium $e$ Taenia crassiceps para o imunodiagnóstico da neurocisticercose foi avaliada por meio de reações de ELISA em amostras de líquido cefalorraquidiano. Anticorpos IgG anti-cisticercos foram pesquisados em amostras de líquido cefalorraquidiano de 23 pacientes com neurocisticercose e 35 pacientes com outras doenças neurológicas. A reação ELISA com o extrato bruto total de cisticercos de Taenia solium apresentou 91,3\% de sensibilidade e 94,3\% de especificidade, enquanto a sensibilidade e a especificidade da reação ELISA com o extrato total de cisticercos de Taenia crassiceps foram $87 \%$ e 94,3\%, respectivamente. As reações ELISA com o líquido vesicular de Taenia solium ou Taenia crassiceps mostraram 91,3\% de sensibilidade e 97,1\% de especificidade. Considerando os resultados obtidos com as quatro preparações antigênicas, o liquido vesicular de cisticercos de Taenia solium $e$ Taenia crassiceps pode ser útil como fonte de antígenos em reações imunológicas usadas para detectar anticorpos específicos em amostras de líquido cefalorraquidiano de pacientes com neurocisticercose.

Palavras-chaves: Neurocisticercose. Antígenos de cisticercos. ELISA.

Neurocysticercosis is a severe disease caused by the presence of the encysted larval stage (cysticercus) of the tapeworm Taenia solium in the human central nervous system (CNS). It is recognized as a major public health problem in many developing countries and is an increasingly important emerging infection in some developed countries with a high influx of immigrants from endemic $\operatorname{areas}^{161525}$.
The clinical diagnosis of neurocysticercosis is hindered by the great variety and non-specificity of the symptoms ${ }^{6} 1522$. Neuroimaging techniques such as computed tomography (CT) and magnetic resonance imaging (MRI) have been recognized as the gold standard for diagnosing neurocysticercosis ${ }^{22}$. However, in many cases, these techniques may not provide a definitive diagnosis of neurocysticercosis, because the complex

\footnotetext{
1. Departamento de Patologia Clínica, Faculdade de Ciências Médicas, Universidade Estadual de Campinas, Campinas, SP. 2. Departamento de Neurologia, Faculdade de Ciências Médicas, Universidade Estadual de Campinas, Campinas, SP.

Address to: Dr. Cláudio Lúcio Rossi. Departamento de Patologia Clínica, FCM/UNICAMP, Caixa Postal 6111, 13083-970 Campinas, SP, Brazil.

Tel: 55 19 3521-7064; Fax 55 193521-9434

e-mail:clr@fcm.unicamp.br

Recebido para publicação em 31/5/2006

Aceito em 8/2/2007
} 
pathological processes of this disease in the CNS often mimic other infectious or non-infectious diseases ${ }^{714}$. In addition, it is not easy to demonstrate the parasites in some areas of the CNS. CT, and even conventional MRI, may fail to detect cysticercal cysts in the cerebrospinal fluid spaces ${ }^{21}$. In addition to their high cost, these sophisticated procedures are rarely available in most endemic areas of developing countries.

Detection of specific antibodies in cerebrospinal fluid (CSF) samples against T. solium cysticercal antigens using reliable techniques such as enzyme-linked immunosorbent assay (ELISA) has been considered to be an important tool for diagnosing neurocysticercosis, especially when neuroimaging techniques are unavailable or inconclusive ${ }^{514}$. Pigs presenting natural infection with T. solium larvae are generally difficult to obtain, and this has stimulated a search for alternative sources of antigens for immunodiagnosis of neurocysticercosis. The larval form of the related species Taenia crassiceps (ORF strain), which reproduces asexually by intraperitoneal passage through Balb/c mice, has been used as a source of antigens for detecting anticysticercal antibodies in immunological tests 25121317 .

There is no agreement about the best antigen preparation to use in ELISA for neurocysticercosis. Some authors have used crude extracts of whole T. solium or T. crassiceps cysticerci, whereas others have used crude extracts from particular components of the parasites (scolex, membrane or vesicular fluid), or even purified antigens ${ }^{12}{ }^{152}$. In the present study, the performance of whole parasite and vesicular fluid extracts from T. solium and T. crassiceps cysticerci for immunodiagnosis of neurocysticercosis by ELISA in CSF samples was evaluated.

\section{MATERIAL AND METHODS}

Cerebrospinal fluid samples. A collection of $58 \mathrm{CSF}$ samples was screened for the presence of cysticercus-specific IgG, by means of ELISA. The samples were obtained from 23 patients with neurocysticercosis and 35 patients with other neurological disorders (neurosyphilis $[n=4]$, neurotoxoplasmosis $[n=5]$, neurocryptococcosis $[n=5]$, viral meningitis $[n=10]$, multiple sclerosis $[n=6]$ and chronic headache $[n=5])$. The patients with neurocysticercosis had CT and/or MRI results compatible with this disease, whereas the patients with other neurological disorders had no epidemiological and radiological evidence of infection by T. solium. All the patients were recruited at the University Hospital of the State University of Campinas (UNICAMP) (Campinas, São Paulo, Brazil). This study was approved by the Ethics Committee of the School of Medical Sciences, UNICAMP, in accordance with the resolutions of the Brazilian National Ethics Committee.

Cysticercal antigens. T. solium cysticerci were obtained from a heavily infected, freshly slaughtered pig. T. crassiceps larvae (ORF strain) were maintained by intraperitoneal inoculation of cysts into 8 to 12 -week-old female Balb/c mice. Intact T. solium and T. crassiceps cysticerci were washed extensively with sterile phosphatebuffered $0.15 \mathrm{M}$ saline, at pH 7.2 (PBS) and aliquoted into plastic tubes to produce whole cysticercal antigens (TsoW and TcraW), or into Petri dishes to collect vesicular fluid antigens (TsoVF and TcraVF).
The parasites in plastic tubes were resuspended in approximately three volumes of PBS containing $5 \mathrm{mM}$ phenylmethylsulfonyl fluoride (PMSF) and $0.0025 \mathrm{mM}$ leupeptin. The material was then homogenized in an ice-water bath using a Polytron ${ }^{\circledR}$ homogenizer (Brinkmann Instruments, Inc., Westbury, NY, USA) equipped with a PT-20 ST probe (three $30 \mathrm{~s}$ pulses at speed 3, with $30 \mathrm{~s}$ intervals between pulses). The homogenate was then sonicated for $3 \mathrm{~min}$ ( 1 min sonications, with pauses of $1 \mathrm{~min}$ ) in an ice-water bath using a Branson Sonicator (model SX-30) at a power setting of three with a $20 \%$ pulse duty cycle. Protease inhibitors (PMSF and leupeptin) were subsequently added to the sonicated material at the final concentrations described above and the suspension was then stirred gently for $2 \mathrm{~h}$ at $4^{\circ} \mathrm{C}$. Centrifugation of the homogenate at $15,000 \mathrm{xg}$ for $60 \mathrm{~min}$ at $4^{\circ} \mathrm{C}$ resulted in a white floating layer followed by a clear supernatant and the pellet. The floating layer was removed with a Pasteur pipette, and the supernatant was collected and filtered through $0.45 \mu \mathrm{m}$ filters (Millex filters, Millipore Corporation, Bedford, MA, USA).

The parasites in Petri dishes were ruptured individually using two needles, and the vesicular fluid released was collected with a Pasteur pipette and transferred to centrifuge tubes. The fluid was then centrifuged at $10,000 \mathrm{xg}$ for $30 \mathrm{~min}$ at $4^{\circ} \mathrm{C}$ and the supernatants were sonicated for $1 \mathrm{~min}$ (two $30 \mathrm{~s}$ sonications, with a $30 \mathrm{~s}$ interval between pulses) in an ice-water bath using a Branson Sonicator (model SX 30, Branson Ultrasonics, Danbury, CT, USA) at a power setting of three with a $20 \%$ pulse duty cycle. After sonication, PMSF and leupeptin were added to the vesicular fluid antigen to give final concentrations of $5 \mathrm{mM}$ and $0.0025 \mathrm{mM}$, respectively.

After determining the protein concentrations ${ }^{3}$, the antigen preparations were aliquoted and stored at $-80^{\circ} \mathrm{C}$ until used.

Human serum pools. A human serum pool positive for cysticercosis (CYSP) and a normal human serum (NHS) pool were prepared as previously described ${ }^{2}$. The CYSP was initially used to determine the optimum reagent concentrations for ELISA and, subsequently, as a standard in each ELISA plate. The NHS pool served as a negative control in ELISA.

ELISA. The assay was done as previously described ${ }^{23}$, with the following modifications: the cysticercal antigens were diluted to $3 \mu \mathrm{g}$ of $\mathrm{protein} / \mathrm{ml}$ in $0.1 \mathrm{M}$ carbonate-bicarbonate buffer, at $\mathrm{pH} 9.5$, prior to sensitizing U-bottomed ELISA plates. The CSF samples and the CYSP were diluted to 1:2 and 1:100, respectively, in PBS-Tween containing 1\% bovine serum albumin. Each CSF sample and the CYSP were tested in triplicate with the four antigen preparations in the same plate and the mean absorbance was determined. The final optical density (OD) for each CSF sample and the CYSP was determined by subtracting the mean OD of the three antigen controls in the corresponding plate. The results were expressed as an antibody index (AI) by dividing the final OD of the CSF sample by the final OD of the CYSP ${ }^{2}$. The cutoff value for ELISA was defined as the mean of the results obtained from the 35 CSF samples from patients with no epidemiological and radiological evidence of infection by T. solium plus two standard deviations.

The sensitivity, specificity and diagnostic accuracy for each assay were determined using the $\mathrm{SAS}^{\circledR}$ System for Windows, version 9.1.3 (SAS Institute Inc., Cary, NC, USA). 


\section{RESULTS}

Twenty-three CSF samples from patients with neurocysticercosis and 35 CSF samples from patients with other neurological disorders were tested by ELISA using cysticercal antigen extracts from T. solium cysticerci (TsoW and TsoVF) and T. crassiceps cysticerci (TcraW and TcraVF). Table 1 summarizes the performances of the assays with the four cysticercal antigens. The TsoW-ELISA showed 91.3\% sensitivity and $94.3 \%$ specificity, whereas the sensitivity and specificity of the TcraW-ELISA were $87 \%$ and $94.3 \%$, respectively. The TsoVF-ELISA and TcraVF-ELISA showed 91.3 sensitivity and $97.1 \%$ specificity.

Table 1 - ELISA results for diagnosing neurocysticercosis using different cysticercal antigen preparations.

\begin{tabular}{lccc}
\hline Antigen & Sensitivity (\%) & Specificity (\%) & Accuracy (\%) \\
\hline TsoW & 91.3 & 94.3 & 93.1 \\
TcraW & 87.0 & 94.3 & 91.4 \\
TsoVF & 91.3 & 97.1 & 94.8 \\
TcraVF & 91.3 & 97.1 & 94.8 \\
\hline
\end{tabular}

Tso: Taenia solium; Tcra: Taenia crassiceps; W: whole parasite; VF: vesicular fluid

In the group of 23 CSF samples from patients with neurocysticercosis, 19 were positive with TsoW-ELISA, TcraWELISA, TsoVF-ELISA and TcraVF-ELISA, whereas one CSF sample was negative with the four antigen preparations. In the group of 35 CSF samples from patients with other neurological disorders, one CSF sample from a patient with neurotoxoplasmosis was positive with TsoW-ELISA and TcraW-ELISA, whereas one CSF sample from a patient with neurocryptococcosis was positive with TsoW-ELISA, TcraW-ELISA, TsoVF-ELISA and TcraVF-ELISA.

The highest diagnostic accuracy (A) values were obtained with TsoVF-ELISA and TcraVF-ELISA ( $\mathrm{A}=94.8 \%)$.

\section{DISCUSSION}

The diagnosis of neurocysticercosis frequently depends on a combination of clinical, epidemiological, neuroimaging, and laboratory data. CT and MRI have been considered to be the most reliable tools for diagnosing neurocysticercosis ${ }^{6} 1122$. However, among the many neuroimaging findings for neurocysticercosis, only the presence of cystic lesions showing the scolex has been considered pathognomonic ${ }^{11}$. Due to their high cost and restricted availability, these diagnostic procedures may be of limited use in developing countries with high rates of cysticercosis. Immunological tests have been widely applied for detecting anticysticercal antibodies in serum and CSF samples using different antigen preparations. In these studies, conducted mainly with immunoenzymatic tests, there is marked variation in the performances of cysticercal antigens, with sensitivities ranging from $47 \%$ to $100 \%$ and specificities ranging from $67 \%$ to $100 \% 25122224$.

Few reports have simultaneously compared the usefulness of different antigen preparations from T. solium or T. crassiceps cysticerci for immunodiagnosis of neurocysticercosis using quantitative immunoassays ${ }^{2423}$. In the present report, the usefulness of whole parasite and vesicular fluid extracts from T. solium and T. crassiceps cysticerci for immunodiagnosis of neurocysticercosis was evaluated by quantitative ELISA on CSF samples. Our results showed that T. solium and T. crassiceps cysticercal antigens had similar efficiency, and the best performance was obtained with TsoVF-ELISA and TcraVF-ELISA (91.3\% sensitivity; 97.1\% specificity; $\mathrm{A}=94.8 \%$ ).

Several authors have shown that immunological tests for neurocysticercosis are less likely to react in patients with a single cyst or calcified parasites than in those with multiple, noncalcified parasites $^{6} 11121522$. In the present study, one CSF sample from a patient with neurocysticercosis gave negative results with the four antigens. This patient had neuroimaging results showing a single cyst with the scolex in the cerebral parenchyma.

The greatest difficulty the serological diagnosis of neurocysticercosis has been the cross-reactivity between cysticercal antigens and serum antibodies from patients with other infections, including echinococcosis, gnathostomiasis, strongyloidiasis, angiostrongyliasis, fascioliasis, ascariasis, toxocariasis and schistosomiasis ${ }^{910} 1819$. Although lower crossreactivity has been documented when CSF samples are used, false-positive reactions for neurocysticercosis have been described in patients with neurotoxoplasmosis, neurotuberculosis, and neuroschistosomiasis ${ }^{82023}$. However, it is important to stress that in most studies designed to evaluate the efficiency of antigen preparations for immunodiagnosis of neurocysticercosis, control CSF samples from patients with CNS infectious diseases or other parasitic infections have frequently not been tested. In the present study, cross-reactions with a CSF sample from a patient with neurocryptococcosis were detected with the four antigens. The patient's medical history and the results of neuroimaging studies revealed no signs of neurocysticercosis.

Significant variations are often seen in the ELISA results for neurocysticercosis. These variations are probably related to several factors, including the intrinsic properties of the diagnostic technique. The inclusion of a CYSP, which was tested with all four antigen preparations in every plate, and the expression of the results as an antibody index (AI = CSF sample OD/ CYSP OD) greatly reduced the variability in the reactivity of the ELISA. Production of a CYSP by an international institution and making it available for inclusion in immunological reactions such as ELISA could allow more reliable comparison between the results obtained by different laboratories.

Some studies have showed that ELISA standardized with vesicular fluid from T. solium or T. crassiceps cysticerci may be a potentially useful diagnostic tool for immunodiagnosis of neurocysticercosis ${ }^{251618}$. Our results confirmed that this component of the parasites might be useful as a source of antigen in immunological reactions for detecting specific antibodies in patients with neurocysticercosis. For routine diagnostic purposes, sensitive and specific antigen preparations must be available in cost-effective amounts. Vesicular fluid can be obtained in sufficiently large quantities with relative ease, particularly when T. crassiceps cysticerci are available. 


\section{REFERENCES}

1. Agapejev S. Epidemiology of neurocysticercosis in Brazil. Revista do Instituto de Medicina Tropical de São Paulo 38: 207-216, 1996.

2. Arruda GC, Silva ADT, Quagliato EMAB, Maretti MA, Rossi CL. Evaluation of Taenia solium and Taenia crassiceps cysticercal antigens for the serodiagnosis of neurocysticercosis. Tropical Medicine and International Health 10: 1005-1012, 2005.

3. Bradford MM. A rapid and sensitive method for the quantitation of microgram quantities of protein utilizing the principle of protein-dye binding. Analytical Biochemistry 72: 248-254, 1976.

4. Bueno EC, Scheel CM, Vaz AJ, Machado LR, Livramento JA, Takayanagui OM, Tsang VCW, Hancock K. Application of synthetic 8-kD and recombinant GP50 antigens in the diagnosis of neurocysticercosis by enzyme-linked immunosorbent assay. American Journal of Tropical Medicine and Hygiene 72: 278-283, 2005.

5. Bueno EC, Vaz AJ, Machado LR, Livramento JA. Neurocysticercosis: detection of IgG, IgA and IgE antibodies in cerebrospinal fluid, serum and saliva samples by ELISA with Taenia solium and Taenia crassiceps antigens. Arquivos de NeuroPsiquiatria 58: 18-24, 2000.

6. Carpio A. Neurocysticercosis: an update. Lancet Infectious Diseases 2: 751-762, 2002.

7. Castillo M. Imaging of neurocysticercosis. Seminars in Roentgenology 39: 465473, 2004.

8. Das S, Mahajan RC, Ganguly NK, Sawhney IMS, Dhawan V, Malla N. Detection of antigen B of Cysticercus cellulosae in cerebrospinal fluid for the diagnosis of human neurocysticercosis. Tropical Medicine and International Health 7: 53-58, 2002.

9. Dekumyoy P, Anantaphruti MT, Nuamtanong S, Watthanakulpanich D, Waikagul J, Danis M. Neurocysticercosis: utilizing the cystic fluid antigen from Taenia solium metacestodes for diagnosis by IgG-ELISA. Southeast Asian Journal of Tropical Medicine and Public Health 31: 21-25, 2000.

10. Dekumyoy P, Waikagul J, Vanijanonta S, Thairungroj M, Nakao M, Sako Y, Watanabe S, Ito A. Cysticercosis: IgG-ELISA evaluations of peak 1 antigen and < $30 \mathrm{kDa}$ antigen of delipidized extract of Taenia solium metacestodes. Southeast Asian Journal of Tropical Medicine and Public Health 35: 1-9, 2004.

11. Del Brutto OH, Rajshekhar V, White Jr AC, Tsang VCW, Nash TE, Takayanagui OM, Schantz PM, Evans CAW, Flisser A, Correa D, Botero D, Allan JC, Sarti E, Gonzalez AE, Gilman RH, Garcia HH. Proposed diagnostic criteria for neurocysticercosis. Neurology 57: 177-183, 2001.

12. Dorny P, Brandt J, Zoli A, Geerts S. Immunodiagnostic tools for human and porcine cysticercosis. Acta Tropica 87: 79-86, 2003.

13. Garcia E, Ordoñez G, Sotelo J. Antigens from Taenia crassiceps cysticerci used in complement fixation, enzyme-linked immunosorbent assay, and western blot (immunoblot) for diagnosis of neurocysticercosis. Journal of Clinical Microbiology 33: 3324-3325, 1995.

14. Garg RK. Diagnostic criteria for neurocysticercosis: some modifications are needed for Indian patients. Neurology India 52: 171-177, 2004.

15. Hawk MW, Shahlaie K, Kim KD, Theis JH. Neurocysticercosis: a review. Surgical Neurology 63: 123:132, 2005.

16. Larralde C, Laclette JP, Owen CS, Madrazo I, Sandoval M, Bojalil R, Sciutto E, Contreras L, Arzate J, Diaz ML, Govezensky T, Montoya RM, Goodsaid F. Reliable serology of Taenia solium cysticercosis with antigens from cyst vesicular fluid: ELISA and hemagglutination tests. American Journal of Tropical Medicine and Hygiene 35: 965-973, 1986.

17. Larralde C, Sotelo J, Montoya RM, Palencia G, Padilla A, Govezensky T, Diaz ML, Sciutto E. Immunodiagnosis of human cysticercosis in cerebrospinal fluid. Antigens from murine Taenia crassiceps cysticerci effectively substitute those from porcine Taenia solium. Archives of Pathology and Laboratory Medicine 114: 926-928, 1990.

18. Morakote N, Nawacharoen W, Sukonthasun K, Thammasonthi W, Khamboonruang C. Comparison of cysticercus extract, cyst fluid and Taenia saginata extract for use in ELISA for serodiagnosis of neurocysticercosis. Southeast Asian Journal of Tropical Medicine and Public Health 23: 77-81, 1992.

19. Ng TF, Ko RC. Serodiagnosis of cysticercosis: specificity of different antigens and enzyme-linked immunosorbent assays. Transactions of the Royal Society of Tropical Medicine and Hygiene 88: 421-422, 1994.

20. Pammenter MD, Epstein SR, Rees RT. Cross reactions in the immunodiagnosis of schistosomiasis and cysticercosis by a cerebrospinal fluid enzyme-linked immunosorbent assay. Transactions of the Royal Society of Tropical Medicine and Hygiene 86: 51-52, 1992.

21. Robbani I, Razdan S, Pandita KK (2004) Diagnosis of intraventricular cysticercosis by magnetic resonance imaging: improved detection with three-dimensional spoiled gradient recalled echo sequences. Australasian Radiology 48: 237-239, 2004.

22. Sciutto E, Fragoso G, Fleury A, Laclette JP, Sotelo J, Aluja A, Vargas L, Larralde C. Taenia solium disease in humans and pigs: an ancient parasitosis disease rooted in developing countries and emerging as a major health problem of global dimensions. Microbes and Infection 2: 1875-1890, 2000.

23. Silva ADT, Quagliato EMAB, Rossi CL. A quantitative enzyme-linked immunosorbent assay (ELISA) for the immunodiagnosis of neurocysticercosis using a purified fraction from Taenia solium cysticerci. Diagnostic Microbiology and Infectious Disease 37: 87-92, 2000.

24. Tsang VCW, Brand JA, Boyer AE. An enzyme-linked immunoelectrotransfer blot assay and glycoprotein antigens for diagnosing human cysticercosis (Taenia solium). Journal of Infectious Diseases 159: 50-59, 1989.

25. Wallin MT, Kurtzke JF. Neurocysticercosis in the United States: review of an important emerging infection. Neurology 63: 1559-1564, 2004. 